BNL-66726

Informal Report

USE OF PERFLUOROCARBON TRACER (PFT) TECHNOLOGY

FOR SUBSURFACE BARRIER INTEGRITY VERIFICATION AT THE WALDO TEST SITE

T. SULLIVAN, J. HEISER, G. SENUM, AND L. MILIAN

June 1999 


\section{USE OF PERFLUOROCARBON TRACER (PFT) TECHNOLOGY}

FOR SUBSURFACE BARRIER INTEGRITY VERIFICATION AT THE WALDO TEST SITE

T. Sullivan, J. Heiser, G. Senum, and L. Milian

Brookhaven National Laboratory

Upton, NY 11973-5000

June 1999

Prepared for

Science and Engineering Associates, Inc.

Sante Fe, NM 87505

Research by BNL investigators was performed under the auspices of the U.S. Department of Energy under Contract No. DE-AC02-98CH10886. 
EWMG-SEA1-62599

Use of Perfluorocarbon Tracer (PFT) Technology

For Subsurface Barrier Integrity Verification at the Waldo Test Site

Prepared by

Terry Sullivan, John Heiser, Gunnar Senum, and Larry Milian

Brookhaven National Laboratory

Upton, NY 11973-5000

June 1999 


\title{
Use of Perfluorocarbon Tracer (PFT) Technology For Subsurface Barrier Integrity Verification at the Waldo Test Site
}

\begin{abstract}
Testing of perfluorocarbon gas tracers (PFT) on a subsurface barrier with known flaws was conducted at the Waldo Test Site operated by Science and Engineering Associates, Inc (SEA). The tests involved the use of five unique PFTs with a different tracer injected along the interior of each wall of the barrier. A fifth tracer was injected exterior to the barrier to examine the validity of diffusion controlled transport of the PFTs. The PFTs were injected for three days at a nominal flow rate of $15 \mathrm{~cm}^{3} / \mathrm{min}$ and concentrations in the range of a few hundred ppm. Approximately 65 liters of air laced with tracer was injected for each tracer. The tracers were able to accurately detect the presence of the engineered flaws. Two flaws were detected on the north and east walls, and one flaw was detected on the south and west walls. In addition, one non-engineered flaw at the seam between the north and east walls was also detected. The use of multiple tracers provided independent confirmation of the flaws and permitted a distinction between tracers arriving at a monitoring port after being released from a nearby flaw and non-engineered flaws. The PFTs detected the smallest flaw, 0.5 inches in diameter. Visual inspection of the data showed excellent agreement with the known flaw locations and the relative size of the flaws was accurately estimated. Simultaneous with the PFT tests, SEA conducted tests with another gas tracer sulfur hexafluoride $\left(\mathrm{SF}_{6}\right)$.
\end{abstract}

\section{Introduction}

One of the more promising remediation options available to the DOE waste management community is subsurface barriers. Some of the uses of subsurface barriers include surrounding and/or containing buried waste, as secondary confinement of underground storage tanks, to direct or contain subsurface contaminant plumes and to restrict remediation methods, such as vacuum extraction, to a limited area. Subsurface barriers will improve remediation performance by removing pathways for contaminant transport due to ground water movement, meteorological water infiltration, vapor- and gas-phase transport, transpiration, etc. Subsurface barriers are a remediation option for many of the DOE defense sites and are also considered an important remediation option by the USEPA [1].

To be most effective, the barriers should be continuous and depending on use, have few or no breaches. A breach may be formed through numerous pathways including discontinuous grout application, from joints between panels and from cracking due to grout curing or wet-dry cycling. The ability to verify barrier integrity is valuable to the DOE, EPA, and commercial sector and will be required to gain full public acceptance of subsurface barriers as either primary or secondary confinement at waste sites.

To fully assess a technology, the stakeholders must have tools available to measure the performance capabilities of the technology. The goal of any barrier installation should be a product that is continuous, having as few holes as possible. Until now, no suitable method existed for the verification of an emplaced barrier's integrity. The large size and deep placement of subsurface barriers makes detection of leaks challenging. This becomes magnified if the permissible leakage from the site is low. Detection of small cracks (fractions of an inch) at depths of 100 feet or more has not been possible using existing surface geophysical techniques. Compounding the problem of locating flaws in a barrier is the fact that no placement technology can guarantee the completeness or 
integrity of the emplaced barrier. Several of the DOE programs are investigating variations of permeation grouting and jet grouting to emplace grout barriers. Permeation grouting is plagued by short-circuiting the flow of grout, which can leave large untreated areas. Jet grouting methods require straight boreholes and sufficient overlap of columns to maintain barrier continuity. Often the borehole wanders or the jet is partially obstructed by cobble or varying soil types, leaving a gap in the final barrier. Panel jet grouting may leave gaps between panels and/or at the junctions of horizontal and vertical barrier walls. Cementitious grouts are subject to desiccation and wet-dry cycling cracks. Additionally, at the time of gel formation, separations or "tears" may occur if localized settling takes place.

DOE has a need to develop/refine barrier verification methods to determine the existence, size, and location of breaches in a subsurface barrier. After such determinations, the effect of the breaches may be factored into the performance assessment of the waste site, or, more appropriately, the breaches could be repaired (and the repairs qualified with the same technology).

Gas tracers are a promising technology for barrier verification. Tracers can be injected inside of the barrier and detected in monitoring ports outside of the barrier. The concentrations on the outside can then be related to the integrity of the barrier. Gas tracers can provide information on the location and size of flaws in a matter of days to weeks. During this study, perfluorocarbon tracers (PFTs) were used to detect barrier imperfections.

\section{Perfluorocarbon Tracers}

A tracer is any substance that can be easily or clearly monitored (traced) in the study media. Tracer technologies can be used in transport/dispersion studies, leak detection studies, and material location. Leak detection studies use tracers to locate and estimate leak rates in various scenarios. These can be as simple as colored dyes used to visually locate cracks and holes in tanks or as complex as mass spectroscopy detection of helium to find leaks in vacuum systems. In transport and dispersion studies, tracers are used to tag a medium to determine how it is being dispersed in a surrounding matrix.

Brookhaven National Laboratory (BNL) has developed a suite of PFTs and has incorporated them into barrier continuity verification tests. These tracers were originally used in atmospheric and oceanographic studies and have since been applied to a great variety of problems, including detecting leaks in buried natural gas pipelines and locating radon ingress pathways in residential basements [3].

PFTs can be detected at extremely low levels. Parts per quadrillion are routinely measured. This allows detection of very small breaches in the barrier. A breach can be located by injecting a series of tracers on one side of a barrier wall and monitoring for those tracers on the other side. The injection and monitoring of the tracers can be accomplished using conventional low-cost monitoring methods, such as existing vadose zone monitoring wells or multilevel monitoring ports, placed using cone penetrometer techniques (e.g., Hydropunch). The amount and type of tracer detected on the monitoring side of the barrier will determine the size and location of a breach. It is easy to see that the larger the opening in a barrier, the greater the concentration of tracer is transported across the barrier. Locating the breach requires more sophistication in the tracer methodology. Multiple tracer types can be injected at different points along the barrier, in both vertical and horizontal directions. 
Investigation of the spectra of tracers coming through a breach then gives a location relative to the various tracer injection points.

PFT technology consists of the tracers themselves, injection techniques, samplers, and analyzers. PFTs have the following advantages over conventional tracers:

- Negligible background concentrations of PFTs in the environment. Consequently, only small quantities are needed;

- PFTs are nontoxic, nonreactive, nonflammable, environmentally safe (contains no chlorine), and commercially available;

- PFT technology is the most sensitive of all nonradioactive tracer technologies and concentrations in the range of 10 parts per quadrillion of air (ppq) can be routinely measured;

- PFT technology is a multi-tracer technology allowing up to six PFTs to be simultaneously deployed, sampled, and analyzed with the same instrumentation. This results in a lower cost and flexibility in experimental design and data interpretation. All six PFTs can be analyzed in 15 minutes on a laboratory-based gas chromatograph.

Typically, the PFTs are measured by a capillary adsorbent tracer sampler (CATS) which is a small cigarette-sized glass tube containing a carbonaceous adsorbent specific for the PFTs. This sampler can be used dynamically (flowing a sample through the CATS) or passively (opening only one end to allow the CATS to sample by diffusion). The passive mode allows a time-integrated PFT concentration to be measured in a simple manner. The CATS are shipped back to the laboratory for PFT analysis.

PFTs allow locating and sizing of breaches at depth and have a detection capability of flaws less than an inch in radius. The tracers themselves have regulatory acceptance and are used commercially for nonwaste management practices (e.g., detecting leaks in underground power cables). The major use of tracers will be to verify placement continuity of a freshly emplaced barrier and to recheck corrective actions that may be used to seal or repair a breach. PFTs may also prove useful in measuring some performance parameters (e.g., diffusion coefficient) of some higher permeability grouts (e.g., Portland cement) and will be useful to monitor a barrier to determine the long-term integrity of the walls. Tracers would allow determination of performance losses in containment over the life of the barrier.

\section{Waldo Site Experimental Plan}

The objective of this set of tests was to be able to determine the accuracy with which PFTs could locate and size known flaws in a subsurface barrier. SEA installed a test facility for this purpose; a complete description of the facility and test plan for this project can be found in Reference [4]. The test facility was originally designed to exercise the SEAtrace ${ }^{\mathrm{TM}}$ system under conditions similar to those that would be encountered at a "real" barrier. The test volume consisted of a small-scale barrier with monitoring points both internal and external to the barrier. The shape and the dimensions of the barrier were chosen to be realistic, easily constructed, and capable of allowing a multitude of leak combinations to be tested. A V-shaped trench roughly 5-meters deep and 15- 
meters long was excavated (Figure 1). The side walls and ends of the trench were sloped roughly $45^{\circ}$ from horizontal.

Figure 1. Schematic Overview of the Waldo Subsurface Test Site
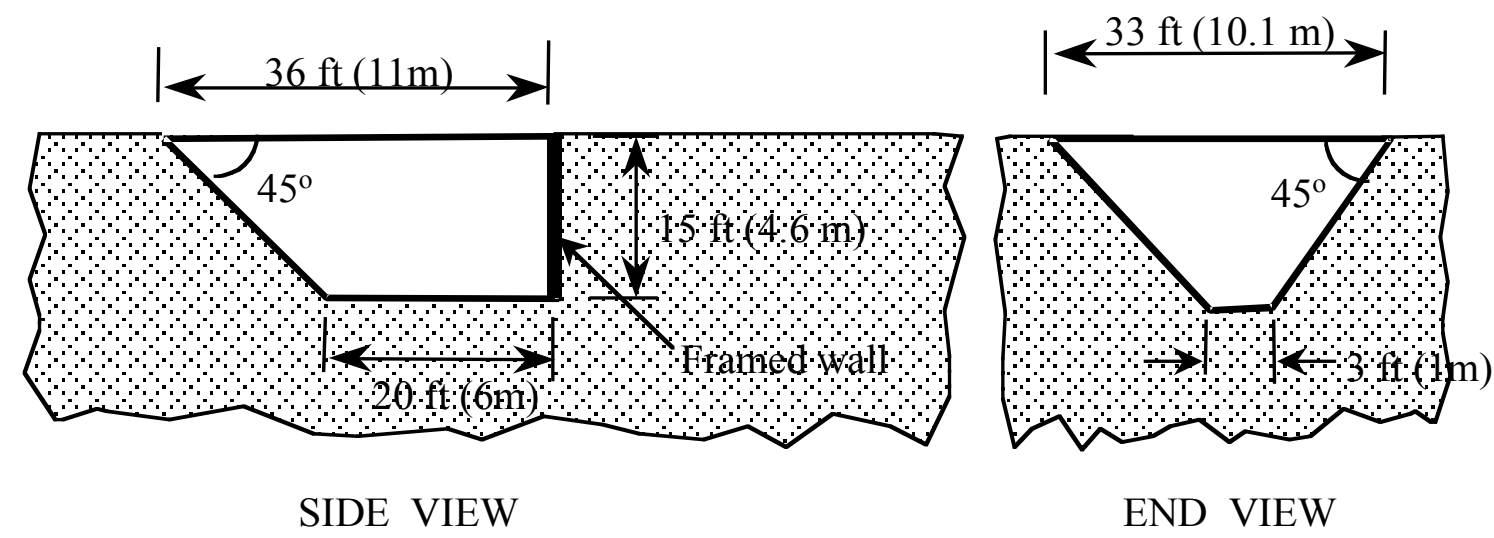

After excavation, the south, east, and west walls of the trench were lined with a 4-inch layer of shotcrete, then a 30-mil thick sheet of plastic to create an impermeable barrier. The north wall, designated as the Framed Wall in Figure 1, was covered with plastic. The region outside of the Framed Wall in Figure 1 was backfilled and is more permeable than the native soils. Once the barrier was completed, the trench was also backfilled.

A series of 23 monitoring wells are placed exterior to the barrier. The wells are separated by approximately six feet at the surface. Within each well, there was one to four monitoring ports at different depths. The distance between ports within a well is also approximately six feet. In total, there are 62 external ports (Figure 2). The depths of the monitoring ports were staggered between wells to provide more efficient coverage of the subsurface region (Figure 2).

The test barrier had six known flaws open during the test. The flaws location and size are presented in Table 1 and Figure 3. 


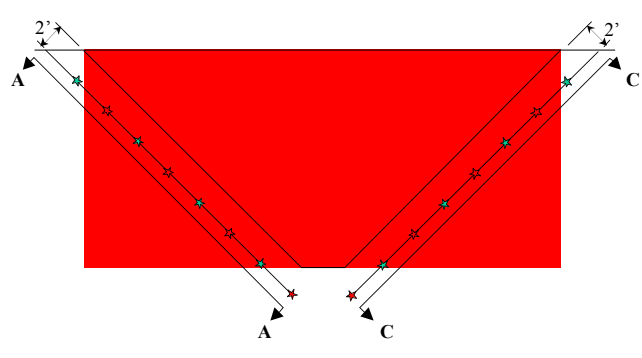

End view (from south) showing ports on East and West panels

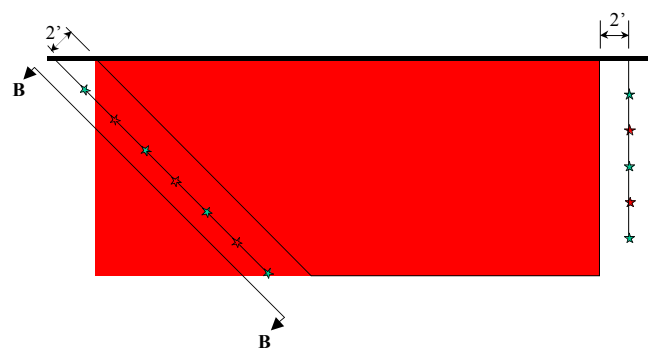

Side view showing ports on North and South panels

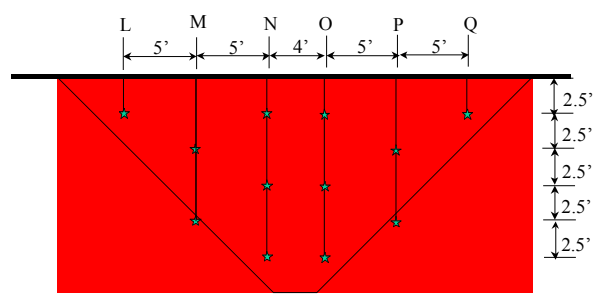

End view (facing North wall)

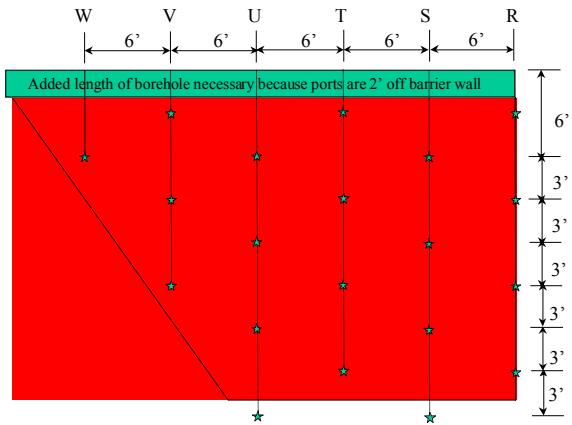

Cross sectional view A-A (West panel)

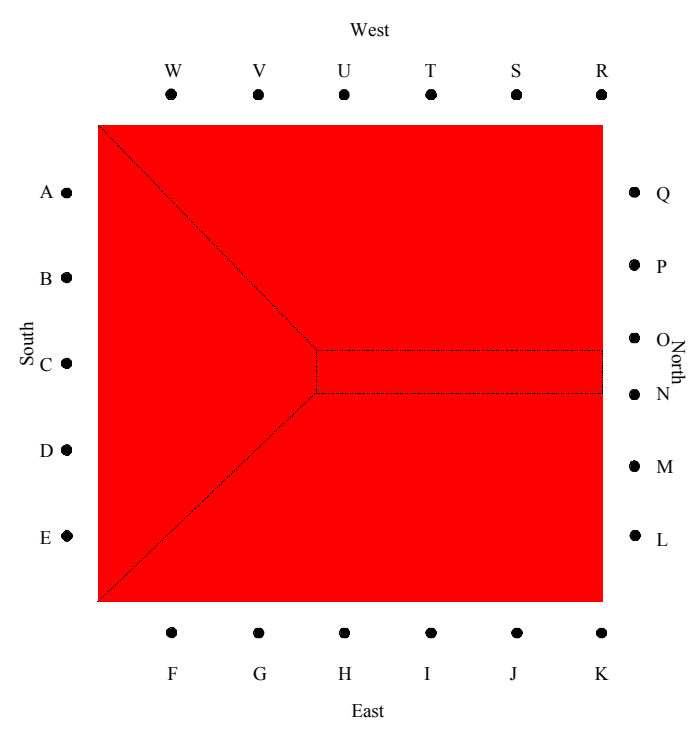

Plan view

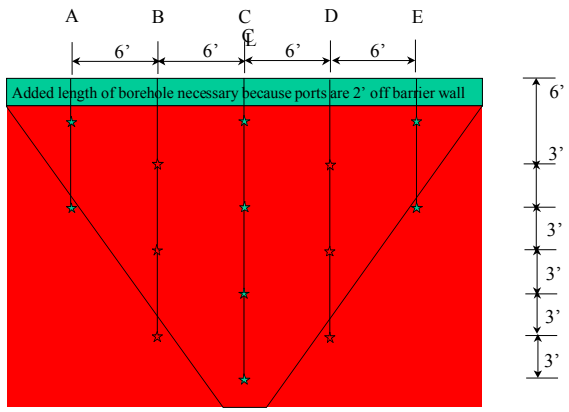

Cross sectional view B-B (South panel)

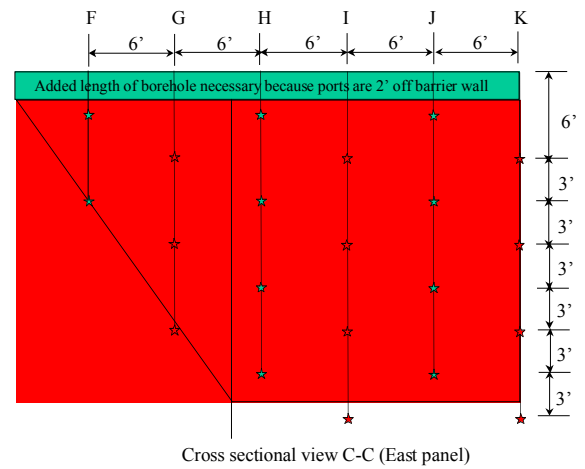

Figure 2. Scaled drawings of the well emplacement and designations. Side and end views of the test facility are shown in the upper right hand corner. A plan view is shown in the upper left-hand corner. Cross sectional views of the slant walls and a side view of the north wall are shown on the bottom half of the page. 
Table 1. Properties of the engineered leaks in the Waldo test barrier

\begin{tabular}{|c|c|c|c|c|c|c|c|c|c|c|}
\hline \multirow[b]{2}{*}{ Panel } & \multicolumn{2}{|l|}{ Location } & \multicolumn{2}{|c|}{ Leak radius } & \multicolumn{2}{|c|}{ Leak diameter } & \multicolumn{2}{|c|}{ Leak area } & \multicolumn{2}{|c|}{$\begin{array}{l}\text { Barrier } \\
\text { thickness }\end{array}$} \\
\hline & $\begin{array}{l}\text { Lateral, } \\
\text { relative to } \\
\text { panel }\end{array}$ & $\begin{array}{l}\text { depth, } \\
\text { relative } \\
\text { to panel }\end{array}$ & (in) & $(\mathrm{cm})$ & (in) & $(\mathrm{cm})$ & $\left(\mathrm{in}^{2}\right)$ & $\left(\mathrm{cm}^{2}\right)$ & $(\mathrm{ft})$ & (m) \\
\hline east & $\begin{array}{l}\text { closest to } \\
\text { north panel }\end{array}$ & center & 7.5 & 19.1 & 15.0 & 38.1 & 176.7 & 1140.1 & 2 & 0.6 \\
\hline east & $\begin{array}{l}\text { closest to } \\
\text { south panel }\end{array}$ & center & 2.0 & 5.1 & 4.0 & 10.2 & 12.6 & 81.1 & 4 & 1.2 \\
\hline south & center & center & 2.0 & 5.1 & 4.0 & 10.2 & 12.6 & 81.1 & 0 & 0 \\
\hline west & $\begin{array}{l}\text { closest to } \\
\text { south panel }\end{array}$ & center & 1.5 & 3.8 & 3.0 & 7.6 & 7.1 & 45.6 & 2 & 0.6 \\
\hline north & $\begin{array}{l}\text { closest to } \\
\text { east panel }\end{array}$ & center & 0.5 & 1.3 & 1 & 2.5 & 0.79 & 5.07 & 0 & 0 \\
\hline north & $\begin{array}{l}\text { closest to } \\
\text { west panel }\end{array}$ & center & 0.22 & 0.56 & 0.44 & 1.20 & 0.15 & 0.97 & 0 & 0 \\
\hline
\end{tabular}


Figure 3. Engineered Flaws in the Waldo Test Site for the PFT Tests

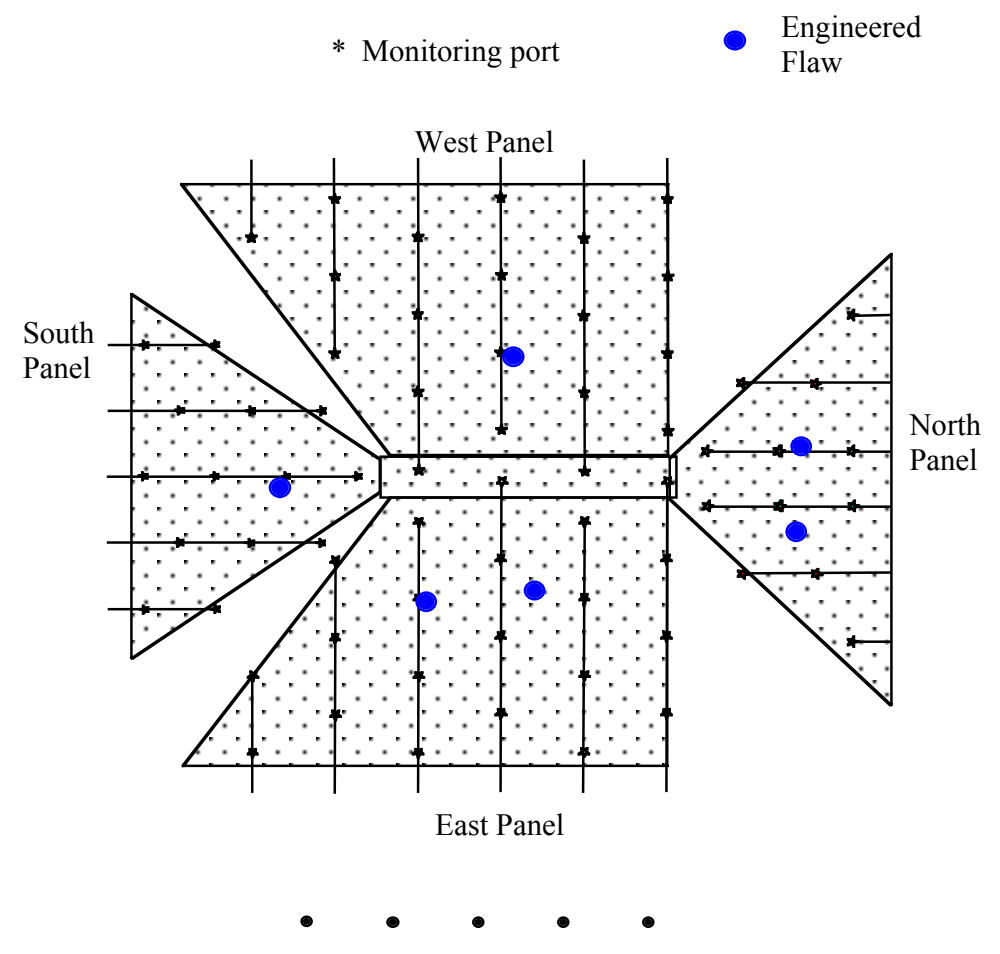




\section{Experiment}

\section{Injection Schedule}

One injection sequence was conducted as part of the test. The test began on November 4, 1998 with the injection of five different PFTs: PMCH, ocPDCH, p-PDCH, PTCH, and PMCP (Table 2). The tracer concentrations in the injected air range from a few ppm to approximately one thousand $\mathrm{ppm}$ (Table 3). The tracers injection flow rates are close to the design air flow rate of $15 \mathrm{~cm}^{3} / \mathrm{min}$ (Table 3). Four of the tracers were injected in the center region of the barrier near the centroid of each wall approximately one to two feet below grade. The fifth tracer, PTCH, was injected outside of the barrier in the fractured shale layer at monitoring port 52 on the west wall (Table 2). This tracer will be used in an attempt to gain a better understanding of flow through this layer and the clay and alluvial layers above. The injection continued for three days until November 7, 1998. The location of each injection and monitoring port is labeled in Figure 4. Injection ports are labeled IS, IE, IN, and IW for the four principle directions, south, east, north, and west, respectively. The relative mass as normalized to the PDCB mass of each tracer injected is also presented in Table 3.

Table 2. Chemical acronym, name and formula for PFT tracers used in this study

\begin{tabular}{|l|l|l|}
\hline Chemical Acronym & Chemical Name & Chemical Formula \\
\hline PDCB $^{1}$ & Perfluorodimethylcyclobutane & $\mathrm{C}_{6} \mathrm{~F}_{12}$ \\
\hline PMCP $^{1}$ & Perfluoromethylcyclopentane & $\mathrm{C}_{6} \mathrm{~F}_{12}$ \\
\hline PMCH & Perfluoromethylcyclohexane & $\mathrm{C}_{7} \mathrm{~F}_{14}$ \\
\hline pt-PDCH & Perfluorotrans 1,4 dimethylcyclohexane & $\mathrm{C}_{8} \mathrm{~F}_{16}$ \\
\hline PTCH & Perfluorotrimethylcyclohexane & $\mathrm{C}_{9} \mathrm{~F}_{18}$ \\
\hline
\end{tabular}

${ }^{1} \mathrm{PDCB}$ and PMCP are chemically distinct isomers.

Table 3. Injection location, concentration, flow rate, and relative mass injected

\begin{tabular}{|l|l|l|l|l|}
\hline Tracer & Location & $\begin{array}{l}\text { Injection } \\
\text { concentration }(\mathrm{ppm})\end{array}$ & $\begin{array}{l}\text { Average Flow Rate } \\
\left(\mathrm{cm}^{3} / \mathrm{min}^{1}\right.\end{array}$ & $\begin{array}{l}\text { Relative Mass } \\
\text { Injected }^{2}\end{array}$ \\
\hline PDCB & south interior & 141 & 13.1 & 1 \\
\hline PMCP & east interior & 936 & 25.95 & 13.1 \\
\hline ptPDCH & north interior & 318 & 12.5 & 2.15 \\
\hline PMCH & west interior & 447.5 & 13.45 & 3.26 \\
\hline PTCH & $\begin{array}{l}\text { west exterior } \\
\text { (monitoring port 52) }\end{array}$ & 122 & 4.15 & 0.27 \\
\hline
\end{tabular}

${ }^{1}$ Flow rate measurements were taken initially and after one day. Difficulties with the flow meter prevented further testing. Reported values are the average of the two measurements.

${ }^{2}$ The relative mass is the product of the injection concentration and average flow rate of the tracer divided by the injection concentration and average flow rate of PDCB. 
Figure 4. Plan View of Injection and Monitoring Ports at the SEA Waldo Test Site

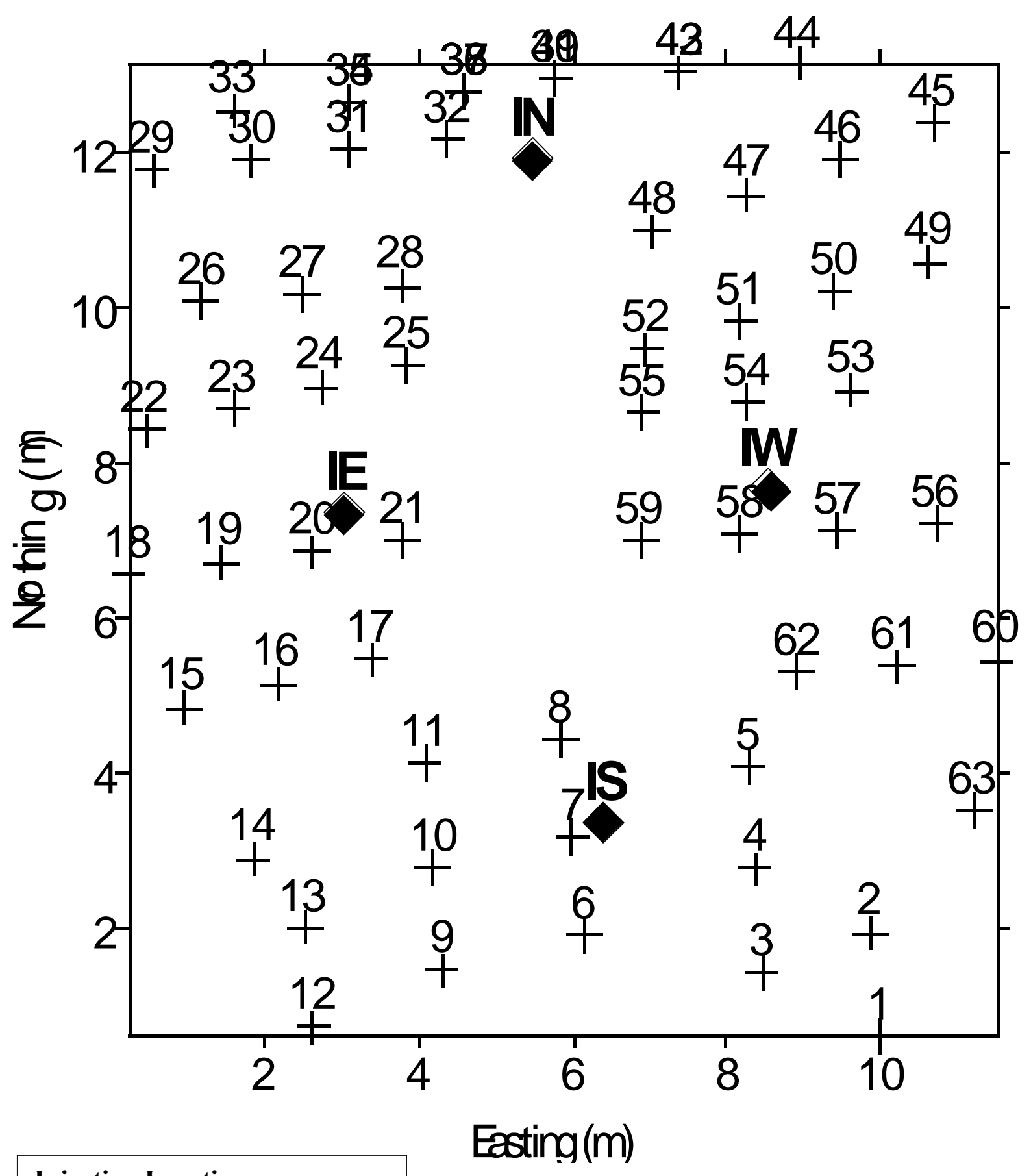

Injection Locations

IN- ptPDCH

IE - PMCP

IS- PDCB

IW- PMCH

Monitoring Ports

+ with a number identifier 


\section{Sampling Procedure}

The sampling procedure included all monitoring ports on a one-day cycle. Monitoring began the day after the injection was started, November 5, 1998, and continued for two weeks, stopping on November 18, 1998. Samples were taken, placed on CATS, and shipped back to BNL for analysis. Sampling of interior ports was necessary to determine the distribution of contaminants inside the barrier after injection. Interior wells were sampled every other day after completion of the injection. A total of 846 samples were taken during the data collection phase of this study.

\section{Results}

The data were analyzed using a gas chromatograph to determine the concentrations of the tracers in each sample. This data was organized by the location of each sample point and a two-dimensional contour plot was generated for each day, wall, and contaminant using Surfer ${ }^{\mathrm{TM}}$. Over 100 contour plots were produced to examine the outcome of the test. The following figures, Figure 5 through 9 , are representative of the findings.

The PTCH tracer that was injected on the outside of the barrier demonstrated diffusion-controlled behavior on the exterior. It was only detected on the interior at one location during one sample collection period. This indicates that the area for flow into the barrier is small compared to the area for flow outside of the barrier. This is consistent with the small flaw sizes as compared to the total area.

Figures 5, 6, and 7 show the time evolution of $\mathrm{PMCH}$ detected in the monitoring ports on the west wall. PMCH was the tracer injected closest to the west wall and appears on the first day of sampling outside of the barrier. The concentrations show a remarkably consistent pattern for the duration of the experiment with the normalized concentration increasing from $10^{-5}$ to almost $10^{-4}$ after 5 days. There is a slow decrease in concentration for the remainder of the experiment. The data support a single flaw in the barrier located at $8.8 \mathrm{~m}$ (Northing) and $-2.65 \mathrm{~m}$ depth.

Figures 8 and 9 show the time evolution of PDCB detected in the monitoring ports on the west wall. PDCB was injected in the interior near the south wall approximately five meters from the injection location of the PMCH. In Figure 8, at early times, PDCB is detected at normalized concentrations of $310^{-7}$ at the lower left corner region of the diagram. This is near the intersection of the south and west walls. The PDCB normalized concentration is two orders of magnitude lower than the levels of PDCB on this wall. At Day 9, PDCB is detected in the region of the flaw detected by PMCH. The normalized concentration in this region increases to a maximum of $210^{-6}$, and it is the highest measured PDCB concentration on this wall. This PDCB data independently confirms the flaw at 8.8 $\mathrm{m}$ Northing and $-2.65 \mathrm{~m}$ in depth. The concentrations at the lower left corner could be from a leak at the seam or from spill over from the hole on the south wall of the barrier. The concentration data for PDCB from the south wall indicate that this is due to movement around the outside of the barrier originating from the flaw in the south wall. This is further supported by the absence of any indication of a leak at the seam from the PMCH data. The use of distinct tracers was essential in determining if the concentration in this region was due to a flaw at the seam or due to transport around the outside of the barrier of tracer originating from another flaw. 
Figure 5. PMCH Contours on Days $1-4$ at the West Wall

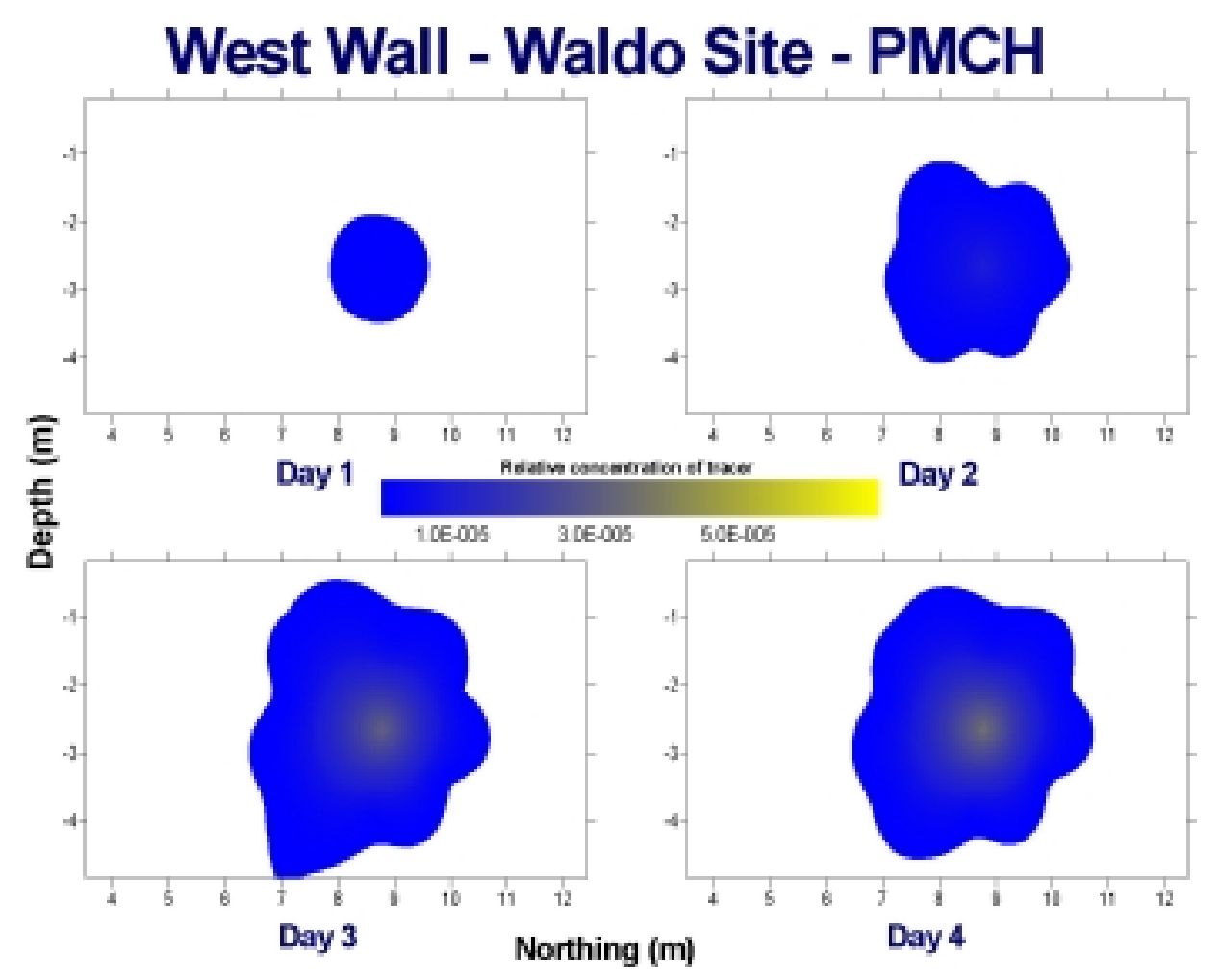


Figure 6. PMCH Contours on Days 5-9 at the West Wall

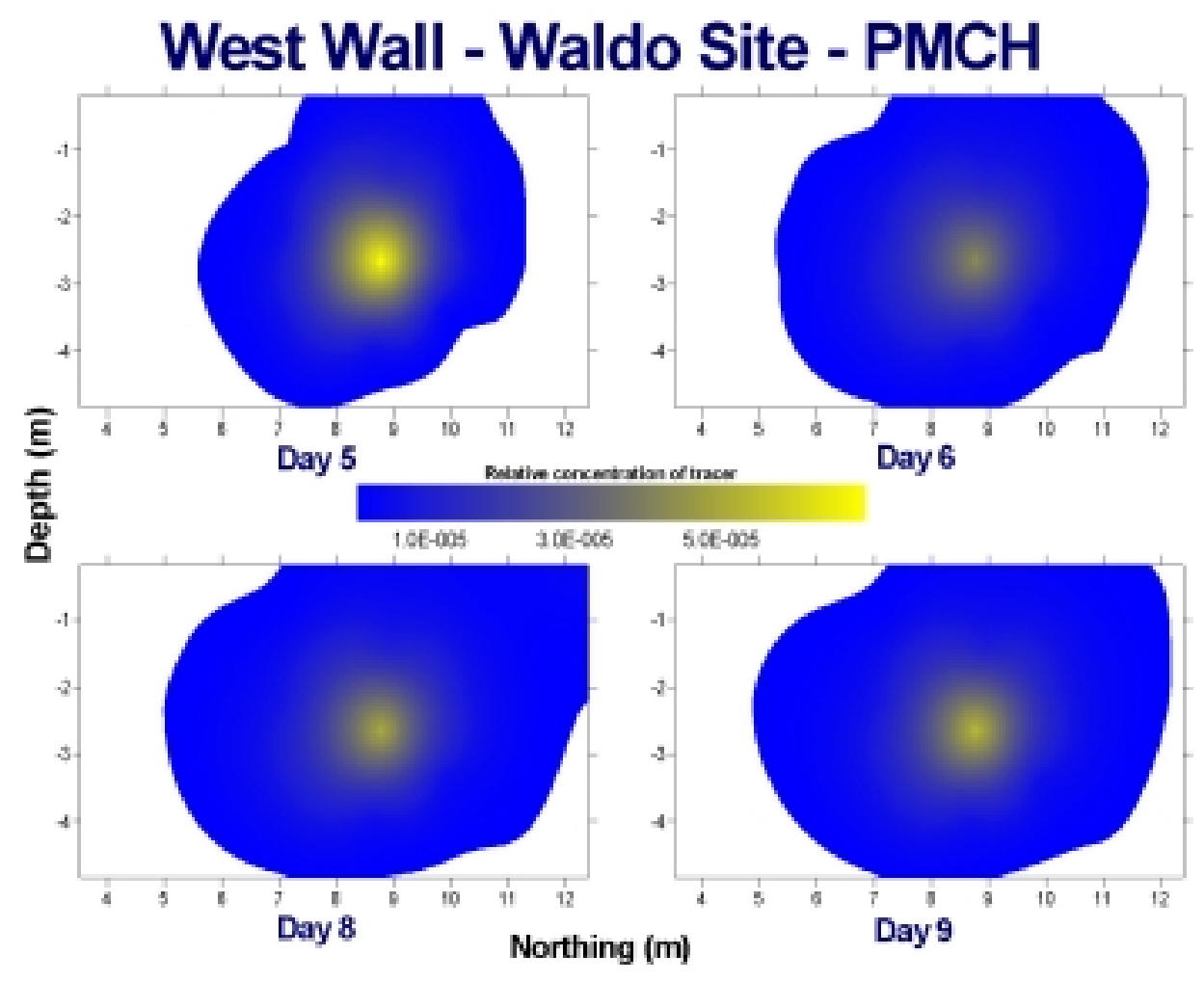


Figure 7. PMCH Contours on Days $10-14$ at the West Wall

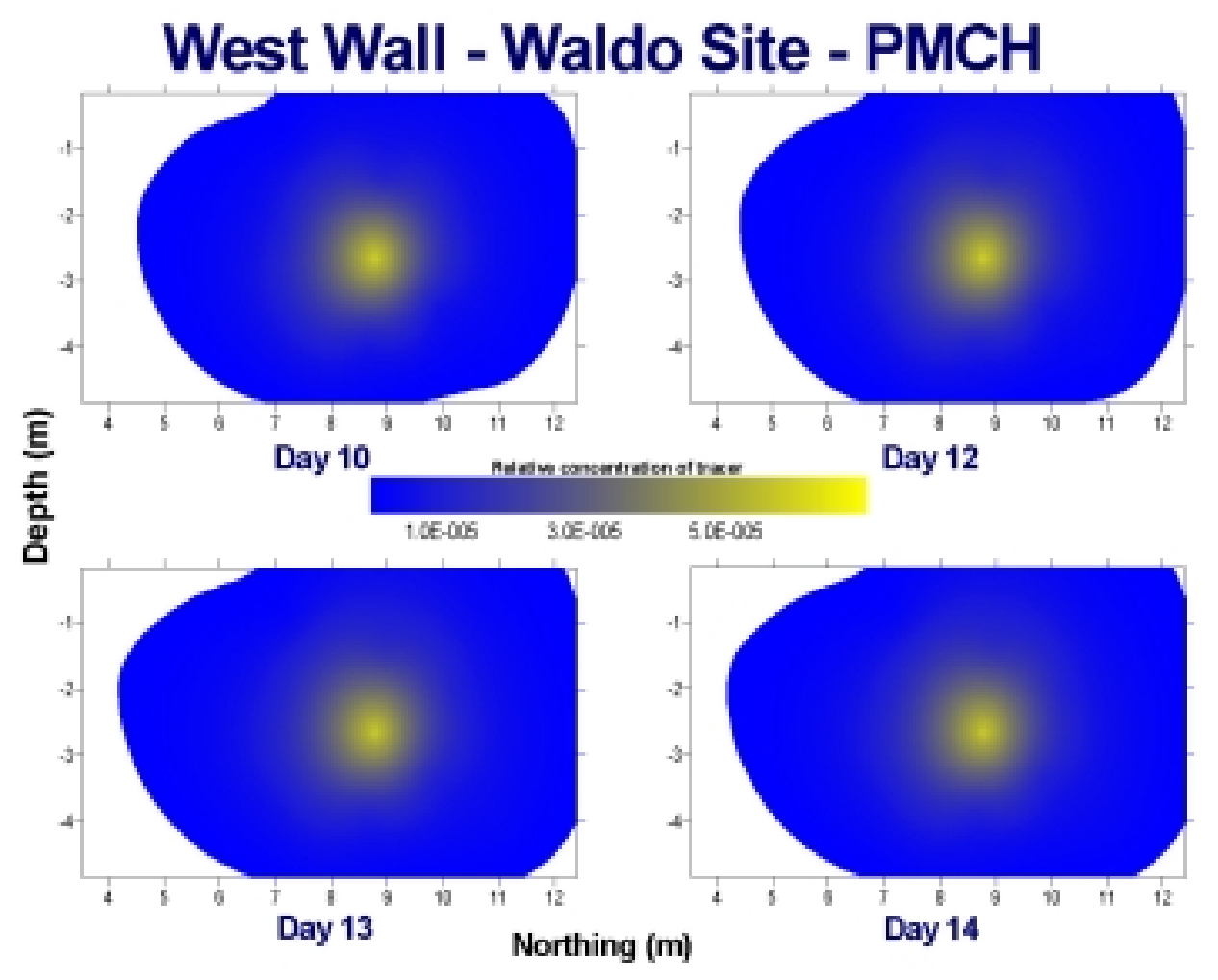


Figure 8. PDCB Contours on Days $1-9$ at the West Wall

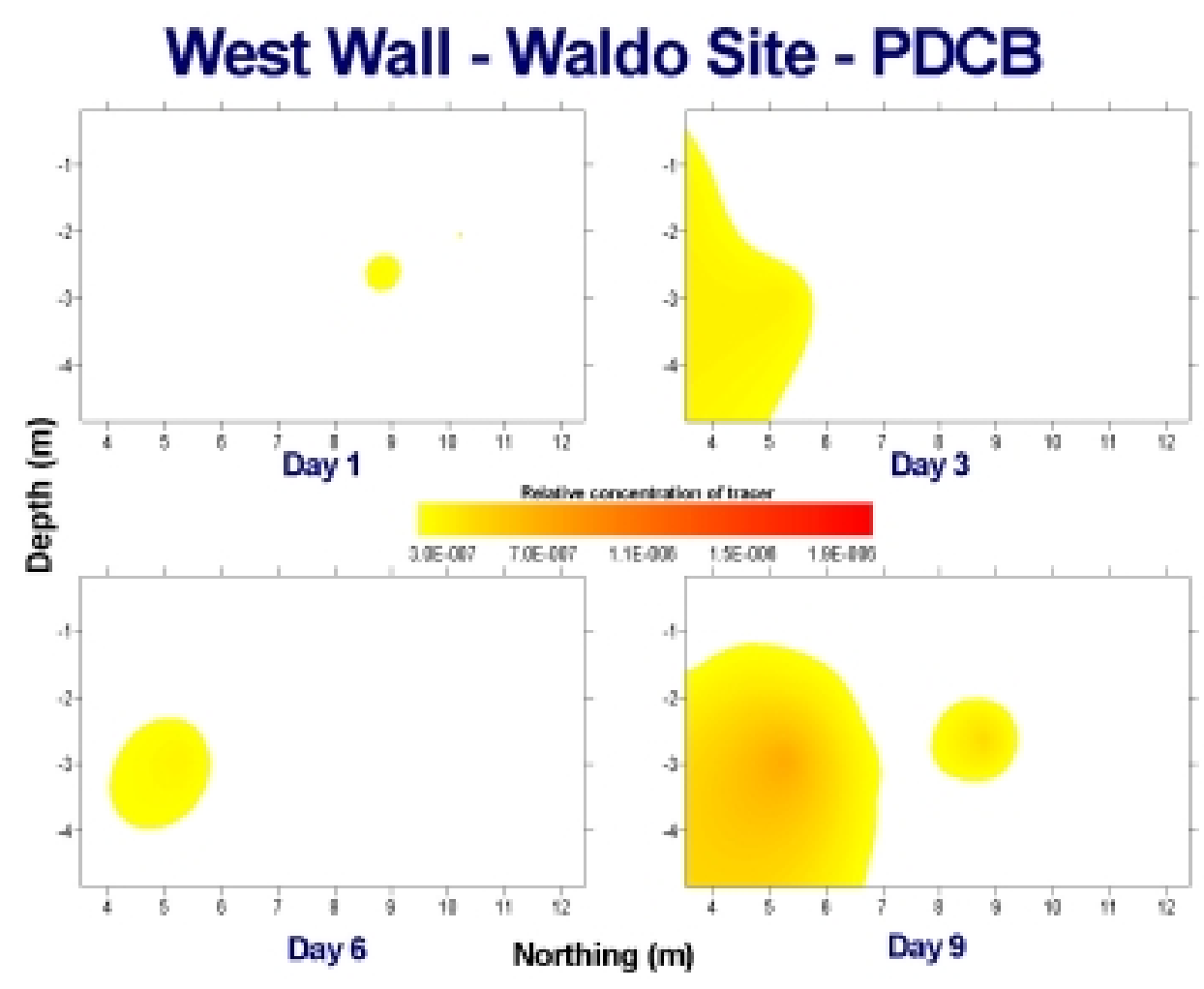


Figure 9. PDCB Contours on Days $10-14$ at the West Wall

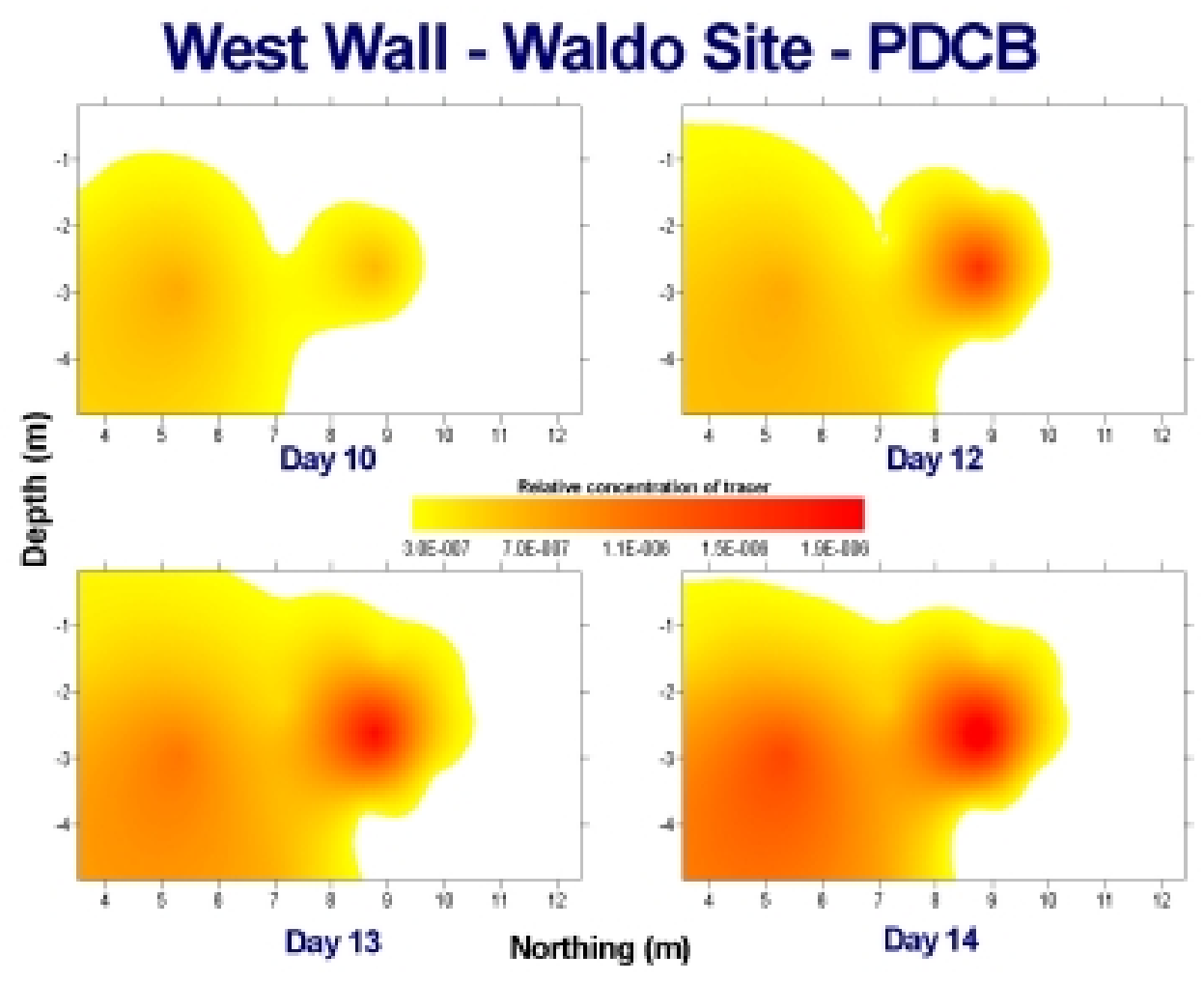


Data from other walls showed similar results. The south wall also had one flaw that was easily detected with the PFTs. The north wall had two small holes that were located by the PFTs. The east wall had three flaws. Two of these were engineered flaws, and the third occurred at the seam between the north and east walls. The non-engineered leak was confirmed by the ptPDCH injected on the north wall and the PMCP injected on the east wall. Table 4 presents the best estimate of the flaw locations in the plane of the monitoring ports based on the PFT data.

Table 4. Flaw locations in the plane of the monitoring ports

\begin{tabular}{|l|l|l|l|}
\hline ID & Easting (m) & Northing (m) & Depth (m) \\
\hline S1 & 6.0 & 3.1 & -3.2 \\
\hline E1 & 3.1 & 12.1 & -3.2 \\
\hline E2 & 3.6 & 9.6 & -3.6 \\
\hline E3 & 2.6 & 7.0 & -3 \\
\hline N1 & 5.8 & 13.0 & -1.5 \\
\hline N2 & 4.6 & 12.8 & -1.4 \\
\hline W1 & 8.25 & 8.8 & -2.65 \\
\hline
\end{tabular}

Flaw locations in Table 4 are defined in the plane of the monitoring ports by direction (Easting, Northing, and Depth). For the north wall, reduce Northing by $0.7 \mathrm{~m}(2 \mathrm{ft})$ to get location on the wall. For other walls, projection is complicated by the 45-degree slope of the wall and the fact that the walls are not exactly parallel to the north or east axis. However, as a first approximation, assume that the walls are parallel. In this case, for the east and west walls, the depth is decreased by $0.5 \mathrm{~m}$, and the Northing is reduced by $0.5 \mathrm{~m}$ on the west wall and increased by $0.5 \mathrm{~m}$ on the east wall. For the south wall, the Depth and Easting are increased by $0.5 \mathrm{~m}$

Figures 10 through 14 present the flow locations projected on the plane of the barrier. Figure 10 presents the plan view with all flaw locations. Figures 11 through 14 represent the side view for the south, east, north, and west walls, respectively. 
Figure 10. Plan View of Injection Port, Monitoring Port, and Flaw Locations

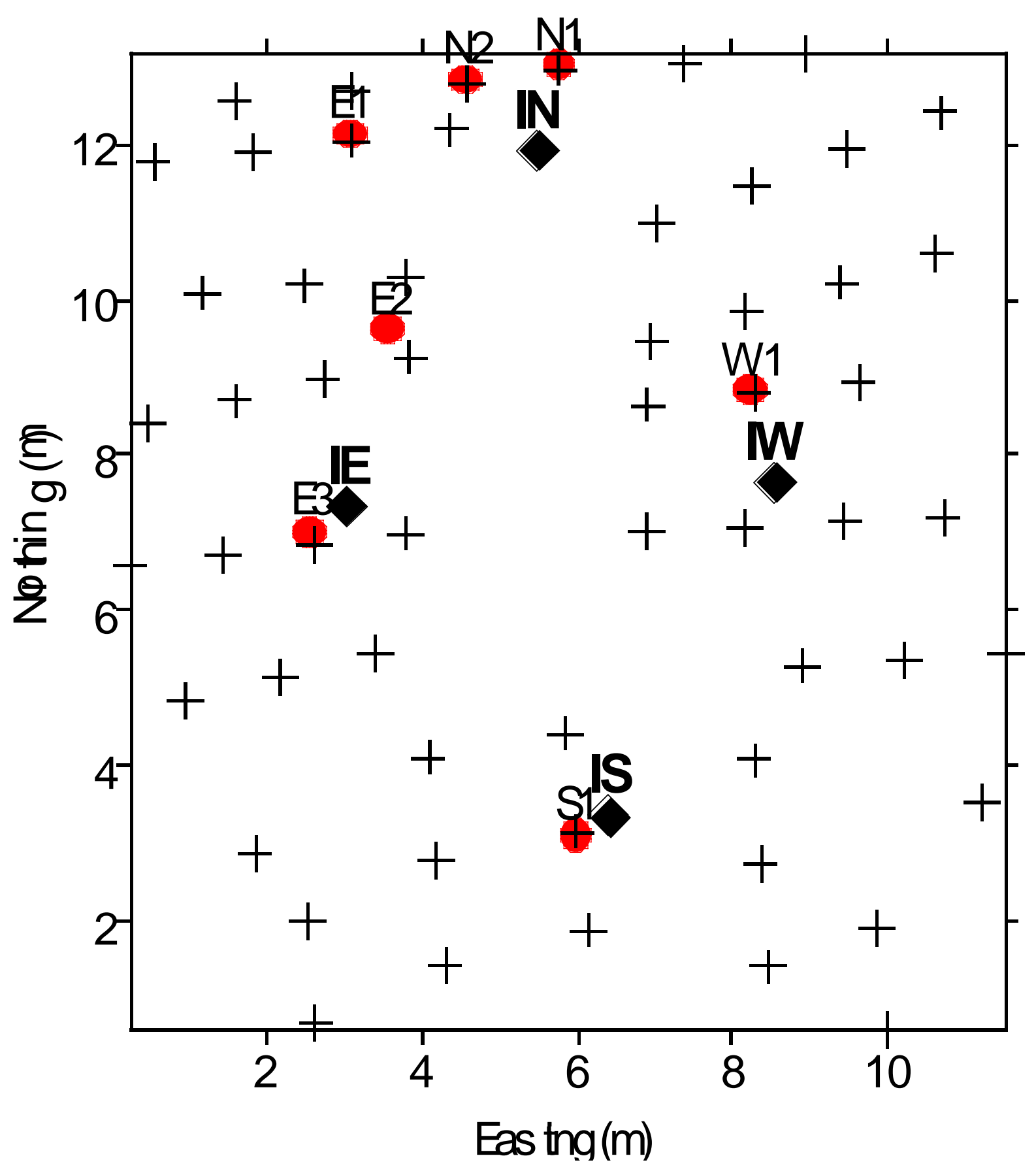


Figure 11. Side View of the Flaw (Circle) and Monitoring Port (+) Locations on the South Wall South Wall

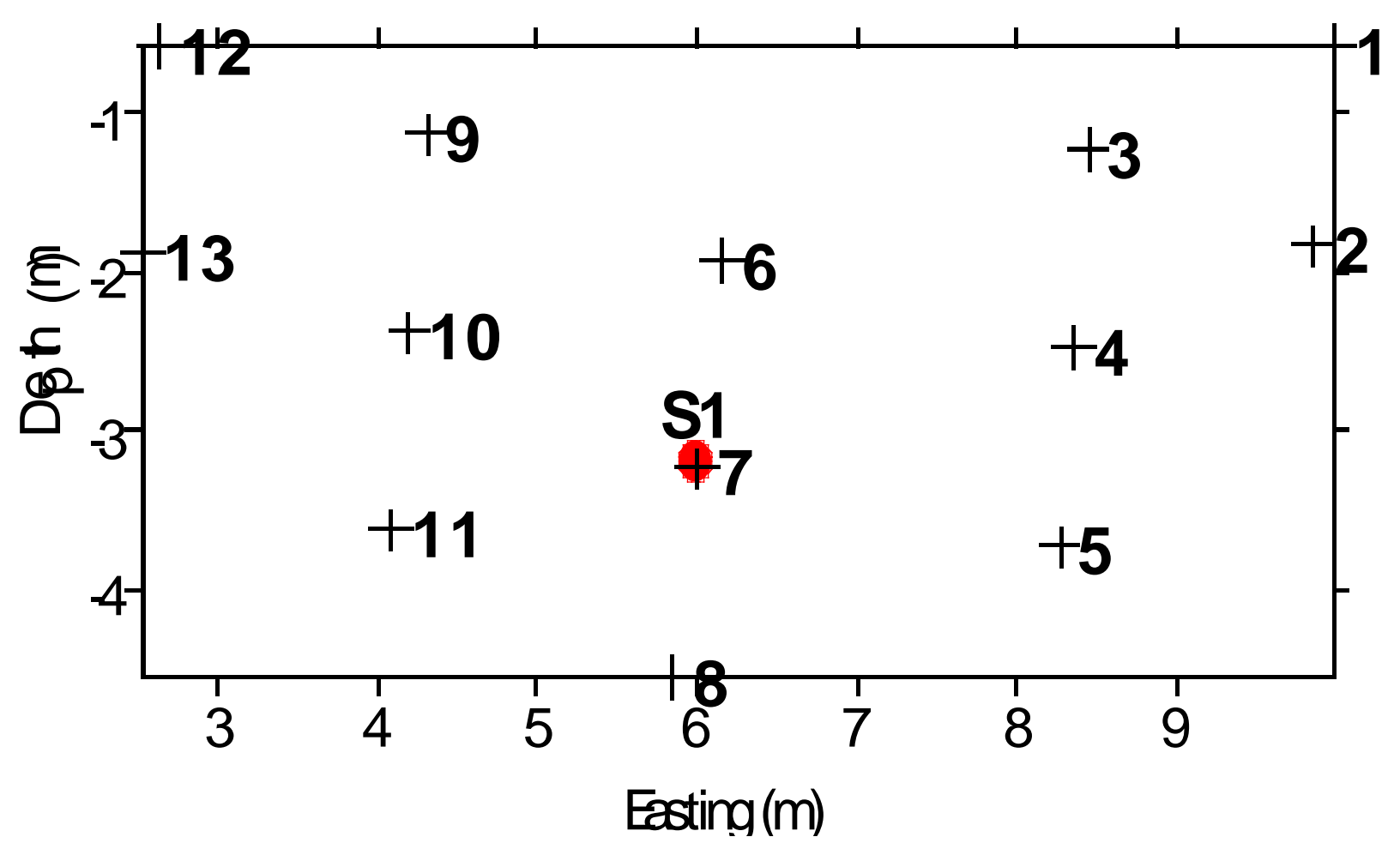


Figure 12. Side View of the Flaw (Circle) and Monitoring Port (+) Location on the East Wall East Wall

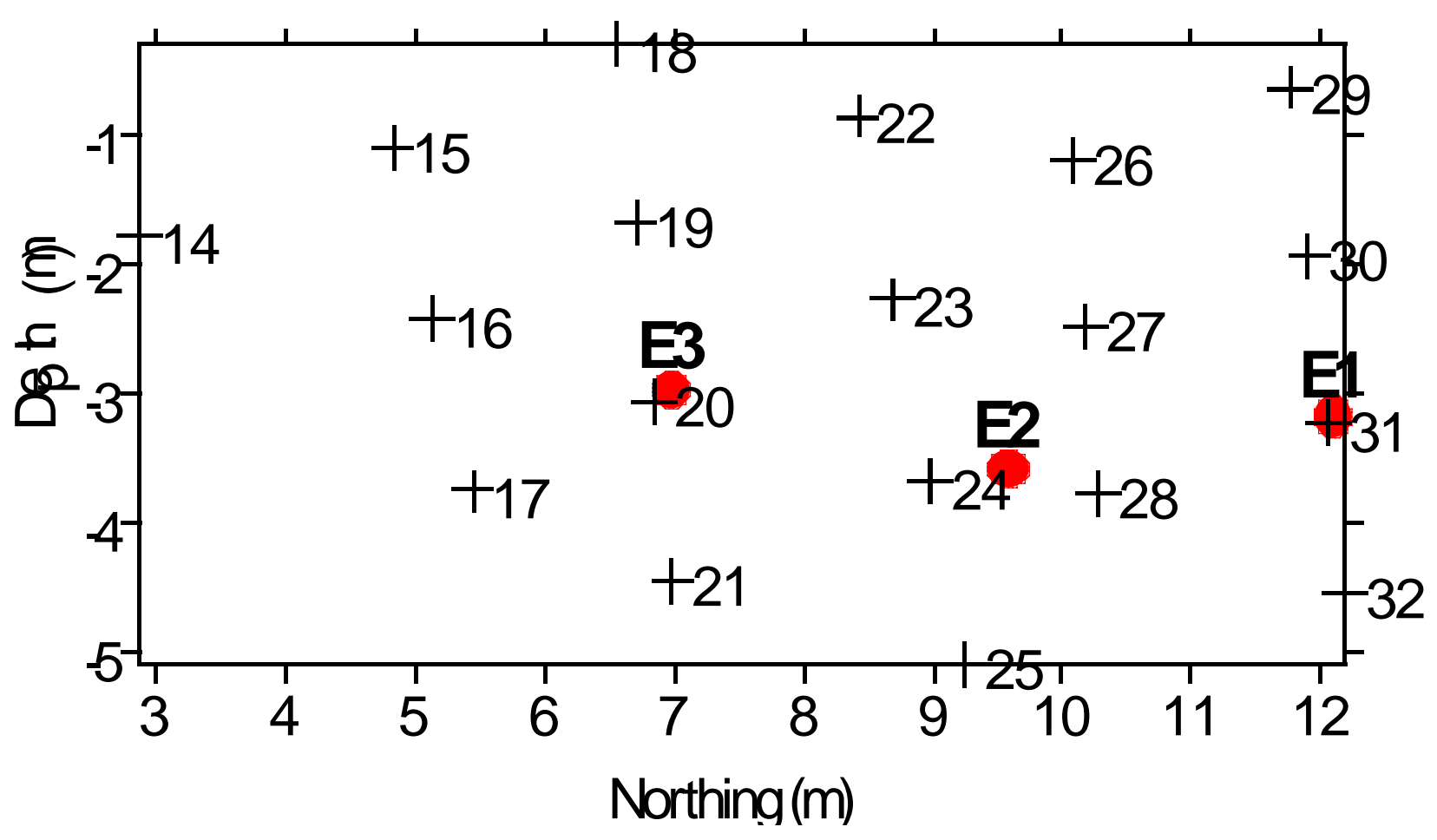


Figure 13. Side View of Flaw (Circle) and Monitoring Port (+) Location on the North Wall North Wall

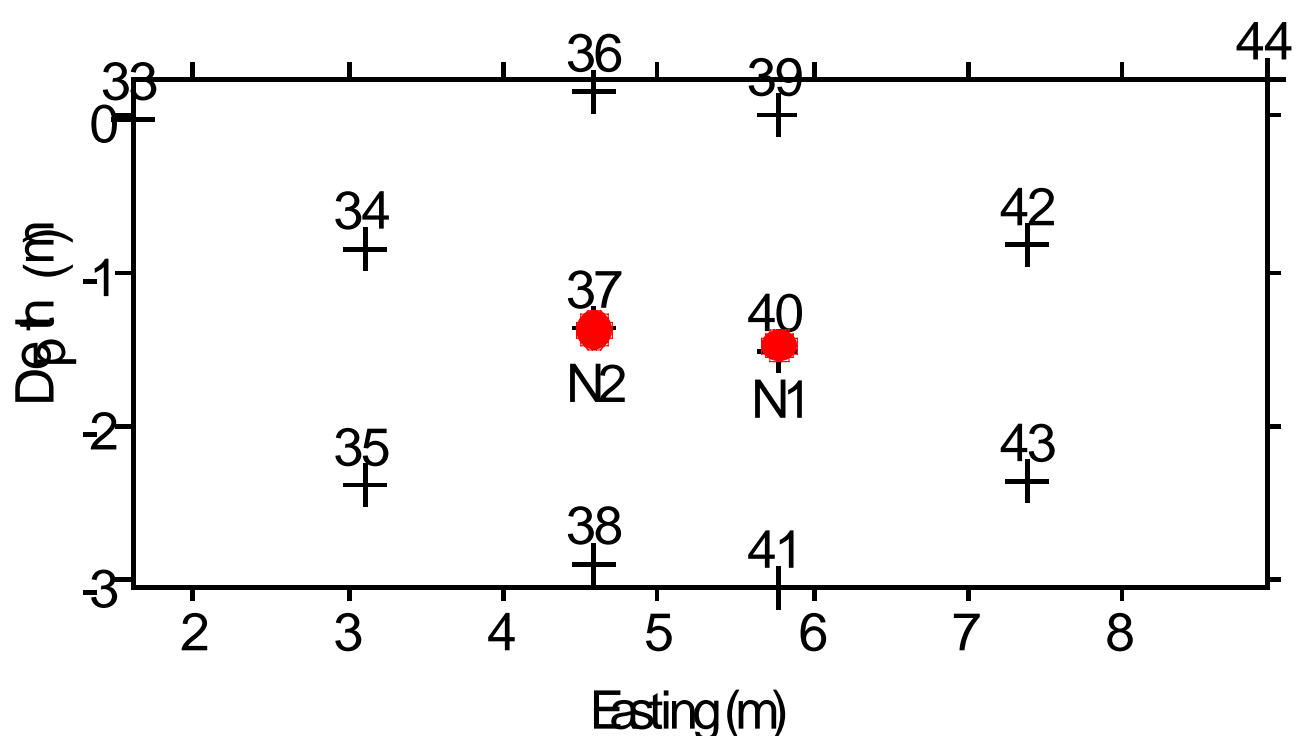


Figure 14. Side View of Flaw (Circle) and Monitoring Port (+) Locations on the West Wall.

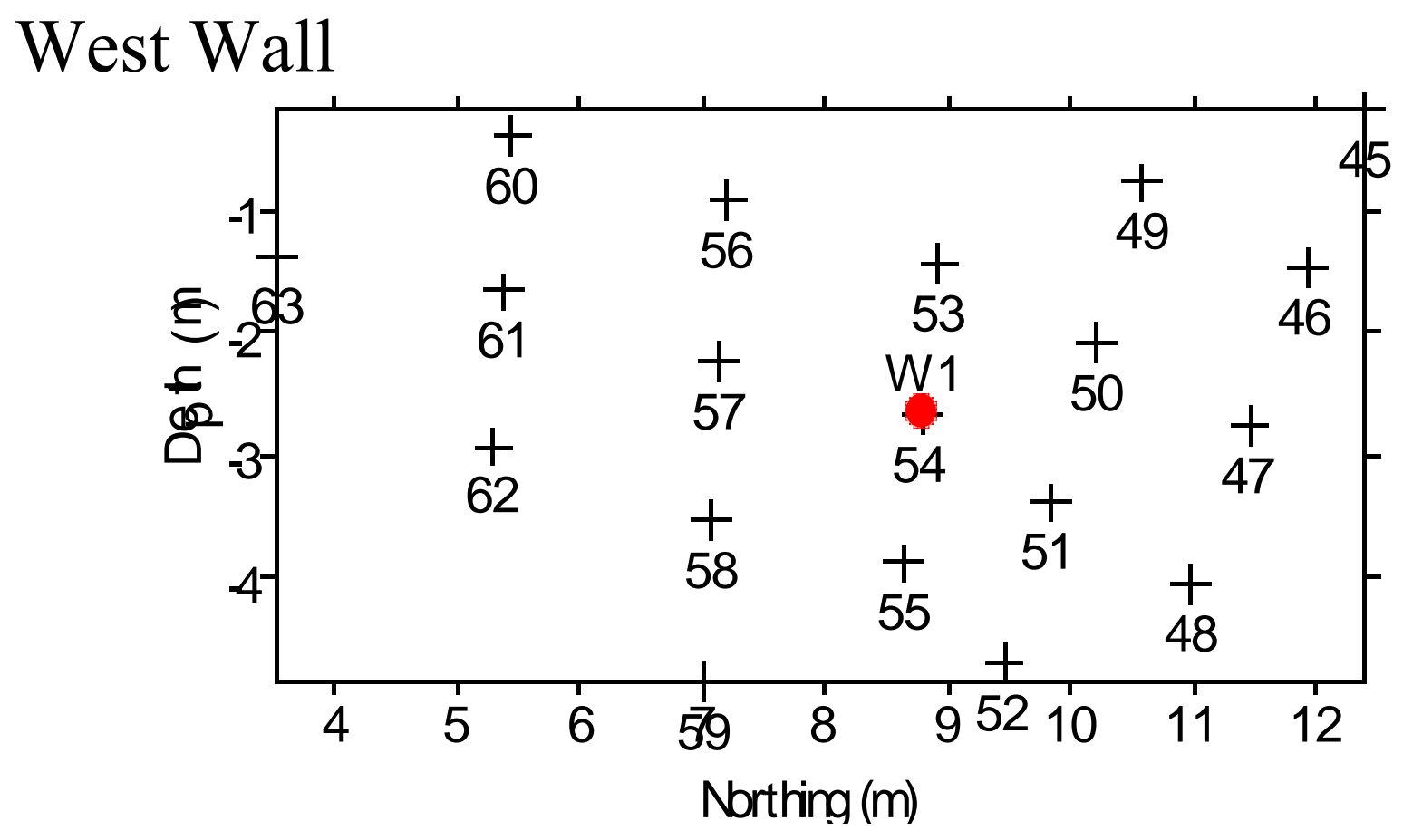


Comparison of the projected flaw locations and the locations of the flaws as detailed in Table 1 and Figure 3 shows excellent agreement. The location of the six flaws is projected within one or two feet of the actual location. This estimate could be enhanced by numerical modeling of the movement of the PFTs in the subsurface. One non-engineered flaw was detected at the seam between the north and east walls.

Without detailed numerical modeling, it is not possible to estimate the flaw size. However, it is possible to examine the relative size of the flaws directly from the data. Assuming that the flaw is small in comparison to the size of the wall, it can be assumed that there is a uniform concentration across the flaw on the interior of the barrier. For a unit concentration on the interior of the barrier, the amount of mass that passes through the wall is directly proportional to the area of the wall. Therefore, to first approximation, the ratio of peak normalized concentrations inside and outside of the barrier is a measure of the area of the flaw, Equation (1). Table 5 presents the peak internal, external, and ratio of external to internal for each wall.

$$
\text { Area } \propto \frac{\text { Peak Exterior Normalized Concentration }}{\text { Peak Interior Normalized Concentration }}
$$

Table 5. Peak internal and external measured concentrations normalized to injection concentration

\begin{tabular}{|l|l|l|l|l|}
\hline Wall & Tracer & $\begin{array}{l}\text { Peak External } \\
\text { Concentration }\end{array}$ & $\begin{array}{l}\text { Peak Internal } \\
\text { Concentration }\end{array}$ & $\begin{array}{l}\text { Peak } \\
\text { Concentration } \\
\text { Ratio }\end{array}$ \\
\hline South & PDCB & $2.90 \mathrm{E}-05$ & $7.80 \mathrm{E}-03$ & $3.72 \mathrm{E}-03$ \\
\hline East & PMCP & $3.50 \mathrm{E}-04$ & $2.50 \mathrm{E}-03$ & $1.40 \mathrm{E}-01$ \\
\hline North & ptPDCH & $4.80 \mathrm{E}-06$ & $1.00 \mathrm{E}-02$ & $4.80 \mathrm{E}-04$ \\
\hline West & PMCH & $7.10 \mathrm{E}-05$ & $9.20 \mathrm{E}-03$ & $7.72 \mathrm{E}-03$ \\
\hline
\end{tabular}

Taking the peak normalized concentration ratio for each wall, the relative size of the flaw areas can be obtained. The area ratio can be obtained from the normalized concentration ratios, correcting for the different flow rates of injection (this is required to place everything on the same basis) as follows, Equation (2):

$$
\text { Area Ratio }=\frac{\text { Interior to Exterior Ratio for Wall } X}{\text { Interior to Exterior Ratio for East Wall }}<\frac{\text { East Injection Gas Flow Rate }}{\text { Wall X Gas Flow Rate }}
$$

The average measured gas injection rates were presented in Table 3. Using the flow rates and the normalized concentration ratios, an estimate of the flaw size can be obtained. Three cases are considered. In the first case, the largest flaw is normalized to a unit area. Thus, this column of the table gives the ratio of flaw areas. In the second case, it is assumed that the flaw is circular and the radius of the flaw is estimated normalizing the largest radius to 1 . The third case considered the largest flaw to be circular with a 7.5-inch radius. The results are in Table 6. 
Table 6. Relative flaw area and flaw radius for each wall (sizes normalized to the largest flaw on the east wall)

\begin{tabular}{|l|l|l|l|l|}
\hline Wall & Tracer & $\begin{array}{l}\text { Area with } \\
\text { maximum } \\
\text { normalized to 1 }\end{array}$ & $\begin{array}{l}\text { Radius with } \\
\text { maximum } \\
\text { normalized to 1 }\end{array}$ & $\begin{array}{l}\text { Radius with maximum } \\
\text { radius normalized to 7.5 } \\
\text { inches. }\end{array}$ \\
\hline South & PDCB & 0.053 & 0.23 & 1.7 \\
\hline East & PMCP & 1 & 1 & 7.5 \\
\hline North & ptPDCH & 0.00713 & 0.084 & 0.63 \\
\hline West & PMCH & 0.106 & 0.32 & 2.4 \\
\hline
\end{tabular}

The data show reasonable agreement with the actual flaw sizes. Normalizing the largest radius to 1 (East wall), the relative radius for the largest hole on each wall is 0.27 for the south and west walls, and 0.067 for the North wall. The data measured the relative flaw size within $25 \%$ of the actual relative flaw sizes.

\section{Conclusion}

Five PFTs were injected in and around a four-sided subsurface barrier that was approximately $10 \mathrm{~m}$ by $10 \mathrm{~m}$ at the surface and $5 \mathrm{~m}$ deep in the test facility at the Waldo Test Site operated by SEA, Inc. Four tracers were injected in the interior of the barrier, one in the center of each wall. The fifth was injected on the outside to confirm that diffusion controlled transport was the controlling transport mechanism. The tests involved a three-day injection scheme followed by a 14-day monitoring period. Monitoring began one day after the start of the injections.

The major findings of the experiment are:

- The PFTs were used to detect a total of seven flaws. This included the six engineered flaws and one non-engineered flaw at a seam between the north and east walls. Multiple flaws were detected on the east (three flaws) and north (two flaws) walls.

- The use of multiple tracers provided simultaneous and independent confirmation of flaw locations.

- The use of multiple tracers allowed monitoring of transport around the barrier. This permitted differentiation between tracers originating from flaws on the other sides of the barrier moving underneath the barrier and flaws in seams of the barrier.

- The PFT data were used to accurately determine the relative size of the flaws in each barrier. The east wall clearly had the largest flaw, the south and west walls had similar size flaws, and the north wall had the smallest flaws. 
Numerical modeling of the hole sizes and locations was beyond the scope of work for this project. However, it is needed to improve definition of flaw size and location.

\section{References}

[1] Siskind, B., and J. Heiser, "Regulatory Issues and Assumptions Associated with Barriers in the Vadose Zone Surrounding Buried Waste," Environmental and Waste Technology Center, Brookhaven National Laboratory, February 1993, BNL-48749(I).

[2] Heiser, J., "Verification of Subsurface Barrier Integrity Using Perfluorocarbon Tracers," TTP CH3-5-PR-19, proposal to U.S. Department of Energy, Office of Technology Development, In Situ Remediation Integrated Program, March 1994.

[3] Deitz, R.N., "Perfluorocarbon Tracer Technology, Regional and Long-Range Transport of Air Pollution," Elsevier Science Publishers, B.V. Amsterdam, The Netherlands, 215-247.

[4] Dunn, S.D., W. Lowry, V. Chipman, and T. Sullivan, "Draft Phase II Test Plan for the Gaseous Tracer Comparative Tests Conducted at the Waldo Subscale Barrier Test Facility", SEA-SF-TR-98, October 1998. 